\title{
POSTPARTUM STROKE AND SYSTEMIC THROMBOLYSIS
}

Raffaella Valenti, MD PhD, ${ }^{1}$ Cristina Sarti, MD PhD, ${ }^{2}$ Antonella Picchioni, MD, ${ }^{2}$ Alba Caruso, MD, ' Domenico Inzitari, MD, ${ }^{2}$ Pasquale Palumbo, MD' 1 ASL Toscana Centro, Ospedale S. Stefano, Prato

2 NEUROFARBA Department, Neuroscience Section, University of Florence, Florence, Italy

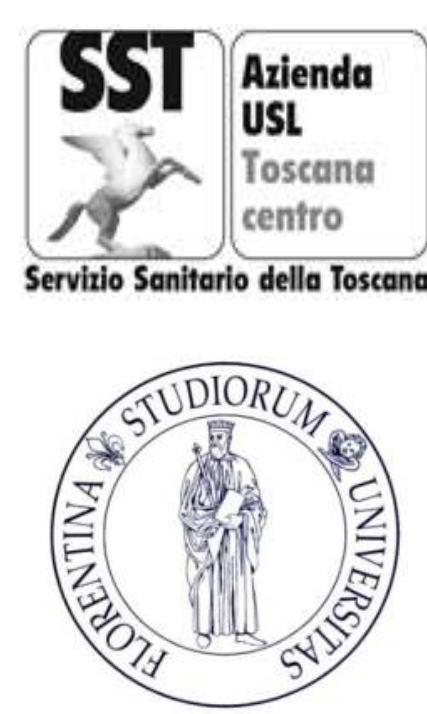

\section{BACKGROUND AND AIMS}

There are very few previously published cases about intravenously applied recombinant tissue plasminogen activator in acute ischemic stroke during puerperium.

\section{CASE PRESENTATION}

We report a 42-year-old woman with postpartum acute ischemic stroke caused by carotid artery dissections treated by systemic thrombolysis. A right-handed woman who was 2 weeks postpartum was admitted to the hospital due to migraine with aura mimic symptoms. In the emergency room, her National Institutes of Health stroke scale was 19 with points received for sudden onset of rightsided weakness and global aphasia. Computed tomography of the brain was negative for hemorrhage and she was given intravenous systemic thrombolysis after fifteen minutes after onset of symptoms. CT angiography of the head and neck showed extracranial left ICA dissection.

One day later she was asymptomatic and MRI showed ischemic stroke in the caudate, centrum semiovale and subcortical temporal left hemisphere. She was discharged home without physical therapy.
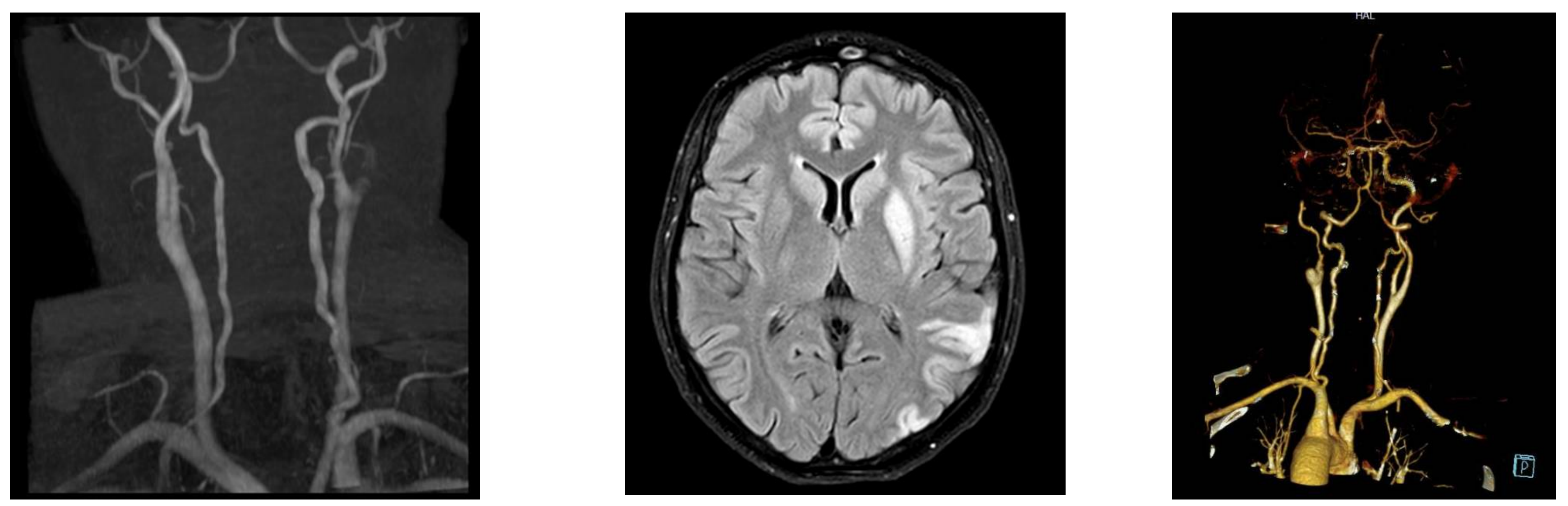

\section{DISCUSSION}

There are only limited data regarding thrombolytic treatment in acute stroke during pregnancy and puerperium. Current acute stroke treatment guidelines--while considering pregnancy as a relative exclusion criterion--do not deal with the postpartum state.

\section{CONCLUSION}

As the condition is rare, randomized controlled trials are not feasible, therefore further reports on similar cases could eventually help us suggest guidelines or at least propose recommendations for the acute thrombolytic treatment of strokes occurring in pregnancy and puerperium 